Shorter operating time and shorter stay in hospital are claimed as advantages in favour of laparoscopy over laparotomy tubal occlusion. In this unit* we have found only a neglible difference between the operating times for laparoscopy and laparotomy tubal occlusion. In a brief survey of matched patients 29 tubal occlusions (11 laparoscopy, 18 laparotomy) were performed by two operators, each with at least six years' experience of each procedure. The mean duration of the operations from preparing the skin to removing the towels at the end of the procedure was 19.2 (range 9-28) min for laparoscopy and 19.4 (range 16-27) $\mathrm{min}$ for laparotomy tubal occlusion.

In this unit the "bottleneck" determining the waiting time for operation is theatre time and only to a lesser extent bed availability. This may be at least in part due to the fact that for some time now it has been our practice to discharge patients $36-48$ hours after either laparotomy or laparoscopy tubal occlusion without ill effect. Perhaps one benefit of laparoscopy is that it has stimulated us to re-examine and streamline our existing methods.

\section{BRIAN ALDERMAN}

Devartment of Obstetrics and Gynaecology,

University of Liverpool

* Contrary to the suggestion by Drs C J Hutchins and N C Curpen (27. September, p 764) there are laparoscopic tubal occlusion.

\section{GMC and overseas doctors}

SIR.-I am deeply touched by the affection shown for overseas people in Lt Col R J Henderson's letter (20 September, p 702), but I feel I must bring a few points to his attention before he begs the British Government to bring in new rules.

Has he ever been anywhere near a centre in the British Isles where ECFMG exams are held? If he has he must have seen hundreds of UK graduates taking that exam. Why are they taking that exam? To improve their basic medical knowledge or technical ability? Is he also not aware of the fact that not a few doctors have permanently taken root in the USA, Canada, Australia, New Zealand, South Africa-need I go on? Of course some of them who went to quench their thirst for knowledge have "slipped off into general practice... or some equally lucrative work." The reasons for UK graduates staying abroad are exactly the same as the reasons for overseas graduates staying in Britain. Would Lt Col Henderson not like to see a law passed to bring them all back to this country, which would be a sadly underdoctored country-if it isn't one already-if his suggestions were to be adopted?

I think that the most constructive thing would be to hold the GMC tests in the parent countries such as India and Pakistan. Let only the $40 \%$ who pass come over, and be given equal opportunity for training and jobs, while the $60 \%$ who fail stay to serve their underdoctored lands, at least until they pass. But no, that was not the suggestion of my colleague who cares so much for us, who suggests that those $60 \%$, till they satisfy the examiners, should work under supervision in Britain at a salary below the standard house officer rate.
I have quite an experience in satisfying examiners in this country-not only examiners but consultants with whom I have worked and, more importantly, my patients. But thanks to the media of television and press suddenly I am a doctor who does not know English and has no basic medical knowledge and technical ability. Would somebody tell me how to tell people at large that I am an exception? Should I carry my testimonials, diplomas, etc with me all the time? This bad publicity does not help the confidence of people we have to treat every day.

I suggest people should stop making scapegoats of overseas doctors and offer better and equal opportunities. After all, it will help the patients ultimately. All those high and mighty people in authority should think and plan constructively before somebody blames the poor state of the economy also on overseas graduates.

Skelmersdale, Lancs

VINAY BHUSHAN

\section{GP obstetrics in the future}

SIR,-I was concerned to read the letter from Wessex on this subject (27 September, p 765). It seemed to me that their proposed scheme was admirable for producing obstetric subspecialists but missed the whole point of general practitioner obstetrics.

It is my experience that patients like to be seen through their pregnancy and labour by their own doctor, and it is certainly rewarding for their doctor to be able to do thisprovided he has suitable experience. The scheme as suggested by Wessex cuts across this ideal and returns the patient to the conveyor belt system which she finds so impersonal and so frightening.

In Norwich we are now enjoying the first year of a "domiciliary in and out" scheme in which we deliver some of our own patients in the hospital labour ward. There we can readily obtain specialist advice if needed. The patient returns home after a short interval. We, and the patients, find this a very satisfying system which seems to accord better with the ideals of family doctoring.

Norwich

F C RUTTER

\section{Risk of cot deaths}

SIR,-I was interested to read your leading article on this subject (20 September, p 664). I was particularly interested by the comment that in Holland, "which has a similar genetic, climatic, and infection background to Britain," the cot death rate is about onethird of ours, and also the same seems to be true of Sweden.

About one year ago my newborn infant patients in the special care nursery of this hospital were put on to a new demineralised whey humanised milk feed (Premium Cow and Gate) because of concern about hypernatraemia and sudden cot death, as well as the concern about neonatal convulsions from the high phosphate level of other more standard milk formulae; also concern about their excess of protein, which might later be involved in producing earlier physical and pubertic development; also concern about the lack of essential unsaturated fatty acids in the more standard milk formulae, with possible increased risk of subsequent vascular atherosis $^{1}$; and finally the positive value of lactose as the carbohydrate in the milk, which might be linked with lessening the risks of gastroenteritis.

Soon after this I spoke to my friend and colleague Professor Henk Visser of the Sophia Hospital in Rotterdam, telling him that I had done this, largely because of my fear of hypernatraemia and sudden cot deaths. His reply was that in Holland in his unit, and I think perhaps elsewhere, they had had milks of this kind in use for the past seven years. When I replied that in this case they ought to have fewer sudden cot deaths in Holland than we had in Britain he said that this was in fact so. $\mathrm{He}$ also mentioned another factor in Continental infant feeding, which was the widespread use of lactic acid-containing feeds, which could lessen the risk of the initial diarrhoea causing dehydration, which is part of the precipitation of the hypernatraemic syndrome. It would be interesting to see if similar feeding practices obtain in Sweden. While there have been no sudden cot deaths in my babies when being fed with the new demineralised whey milk, it is, of course, too soon and the numbers too small to claim that this is an established fact, but it may be important suggestive evidence.

A number of years ago I wrote to the journals ${ }^{2}$ to invite letters from doctors who had seen sudden cot deaths in wholly breastfed infants, and I received only two replies. Almost certainly there are many causes of sudden cot deaths, but it seems likely that an early change to breast-feeding for an adequate period of time or, if this is impossible, then the feeding of one of the new humanised demineralised whey milks could well reduce very considerably the number of these tragic sudden cot deaths and the associated shattering family crises which frequently accompany such a sudden unexpected loss of a young baby.

ROBERT WIGGLESWORTH

Kettering and District General Hosp:tal, Kettering, Northants

1 Osborn, G R, The Incubation Period of Coronary 2 Wigglesworth, R, British Medical fournal, 1971, 3, 482 .

Carrier solutions for low-level intravenous insulin infusion

SIR,-We $\mathrm{W}^{1}$ and two other groups ${ }^{2} 3$ have found low-dose infusion of insulin to be a convenient and effective treatment for diabetic ketoacidosis. An important question arising from these studies was whether it was necessary to include protein in the infusate to prevent adsorption of insulin to the infusion apparatus. Page et $a l^{2}$ did not use protein in some patients in their series and, from plasma insulin measurements, concluded that it was unnecessary in their infusion system (soluble insulin $1200 \mathrm{U} / 1$ in saline delivered by pump at $5 \mathrm{ml} / \mathrm{h}$ ), in which a fresh insulin solution was used every four hours. Dr E W Kraegen and his colleagues (23 August, p 464) found 60-80\% losses of insulin from physiological saline solutions $(40 \mathrm{U} / 1)$ delivered by paediatric drip set from 
$500-\mathrm{ml}$ glass or plastic containers. Loss of insulin could be eliminated by including $3.5 \%$ polygeline in the infusate.

The extent of insulin adsorption from protein-free solutions depends on the concentration of hormone, the nature of the surface, the duration of contact with the surface, and the rate of flow of the solution." We routinely use albumin but have compared the recoveries of insulin, measured by radioimmunoassay, ${ }^{5}$ from solutions prepared with or without albumin through our infusion system. Solutions of soluble insulin (4000 $\mathrm{U} / 1$ in $0.154 \mathrm{M}$ saline) were delivered from 50-ml BD Plastipak syringes connected to an Argyle Medicut via a $200-\mathrm{cm}$ Portex manometer connecting tube. The infusates from two syringes, one containing $10 \mathrm{~g}$ human albumin/1 (Scottish National Blood Transfusion Association, Edinburgh) were collected into polystyrene tubes over timed intervals. The rate of delivery was $1 \mathrm{ml} / \mathrm{h}$. The albumin-free solution was collected into a solution of aqueous albumin to prevent further insulin adsorption.

The recoveries of insulin from $2-\mathrm{ml}$ aliquots of the solution with albumin collected between $0-2,2-4,4-6,6-8,8-10$, and $10-24 \mathrm{~h}$ were constant $(92-109 \%)$. In contrast, recoveries from the solution without albumin were $82 \%, 77 \%, 62 \%, 29 \%, 41 \%$, and $33 \%$ respectively.

The data indicated major losses of insulin from the solution without albumin which increased with time. This could be a serious problem, especially if very low rates of insulin infusion (1-2 $U / h$ ) are used or if infusions are continued for long periods from the same syringe. The extent of insulin adsorption is likely to vary with the infusion system used. We think it would be safer to include protein (albumin or polygeline) in infused solutions of insulin.

PeTER SEMPLe JOHN G RATCLIFFE W G MANDERSON

MRC Blood Pressure Unit,

Western Infirmary, Semple, P F, White, C, and Manderson, W G
British Medical fournal, 1974, 2, 694.

Page, M M, et al, British Medical fournal, 1974

Kidson, W, et al, British Medical foumal, 1974

Weisenfeld, S, et al, Diabetes, 1968, 17, 766

Albano, J D M, et al, Acta Endocrinologica, 1972,
70, 487.

\section{MRCP (UK) part II}

SIR,-The colleges have been reviewing the common part II examination for the MRCP (UK) diploma, which was introduced in October 1972. On the whole we are pleased with the examination and are satisfied that it is performing its function as an entry examination to higher specialist training.

There is one point which is receiving special attention. The Joint Committee on Higher Medical Training recommends that those intending to specialise in medicine should enter higher specialist training four years after graduation and should usually achieve their membership during general professional training. Our experience suggests that the entry of paediatricians into higher specialist training is delayed because of the difficulties they encounter at present in the common part II written examination. Candidates may now opt to be examined in the orals and clinicals in either genera medicine or paediatrics. The written section of the part II examination require a fair degree of experience in adult medicine and analysis shows that candidates opting for paediatrics are at a disadvantage in the current written examination, particularly in the data interpretation and projected material sections (even though some paediatric questions are included).

The colleges have therefore agreed that a paediatric written section will be introduced as soon as possible in 1977. The standard of the examination will remain the same and some questions will be common to both the paediatric and general medicine options. Those candidates who have succeeded in the membership examination through the paediatric option should not in any way be considered to be "specialists" without undergoing higher specialist training as laid down by the Joint Committee on Higher Medical Training.

\section{JOHN CROFTON \\ Royal College of Physicians of Presiden}

FERGUSON ANDERSON

Royal College of Physicians and Surgeons of Glasgow

CYril a Clarke

Royal College of Physicians of London

Central MRCP (UK) Office,

London NW1

\section{Jobs for women doctors}

SIR,-Many women doctors, as is well known, experience difficulties in finishing specialist training and in finding suitable posts when they are unable to work full time, travel far to work, or move house.

To help women to find their way through the jungle of committees which control parttime postgraduate training and to give general advice and help, the Medical Women's Federation has appointed one or more members in each regional health authority who are willing to be consulted by any woman troubled about her career.

Anyone who would like help of this sort is warmly invited to write to me for the name of the doctor nearest to the inquirer's home.

JEAN LAWRIE Tavistock House North, Tavistock Square,

Hon Secretary,

\section{Salary increments and anti-inflation policy}

SIR,-Few would argue against a fair antiinflation policy which asked the larger sacrifice of the higher-paid members of society. It does seem, however, that in the case of consultants this is not to be so.

It is enormously disheartening for a younger consultant, who has somehow struggled with his family through the training years on the minimum salary his employer could get away with paying him and contending at the same time with roaring inflation, to learn that the Department of
Health and Social Security, in applying the Government's anti-inflation policy to the profession, has decided that different groups of consultants are to be treated in differen ways. While all who earn over $£ 8500$ a year will forgo any new increase in their pay scales which the Review Body next year might normally have recommended, it is only those younger consultants still climbing up the increment ladder who will have the privilege of making a second heavy contribution to "a year for Britain" by having at least one full increment (£789) permanently withheld from their contractual salary. No such equivalent sacrifice will be asked of those older consultants fortunately and comfortably on the top of the salary scale. This extraordinary situation, whereby the less well-off are to be penalised the most, can hardly be said to be a fair application of "the fight against inflation"

It is difficult to understand how increments can be withheld selectively from those consultants on the second, third, and fourth points, presumably because the DHSS considers that to pay them would be a breach of the Government's policy, when those on the first point will receive their full entitlement, which, representing as it does the equivalen of $£ 15$ a week, certainly exceeds the $£ 6$ limit, unless of course there is some obscure and subtle difference between the first and subsequent increments on the consultan salary scale.

Quite apart from all this, the mere fact that our employer feels itself able to interfere with existing contracts of employment has very sinister implications. The salary arrangements in force at any time are surely an integral part of a current contract of employment, having been previously negotiated and agreed between the profession and the DHSS. Any unilateral interference with a contract by the DHSS must put it, as employer, in breach of contract with the employee-unless, of course, a statutory pay freeze was introduced as the law of the land This is apparently not the case and indeed the Government's anti-inflation policy is based on voluntary agreement and not on statute and is concerned with new pay rises over and above existing rates of pay.

It must be in the interests of the profession as a whole to challenge fiercely any attempt by our employer to meddle with or alter previously agreed contracts of employment which are in operation unless a highly dangerous precedent is to be set for the future, particularly when one appreciates the present efforts to produce a full-time salaried monopoly medical profession and health service.

Victoria Central Hospital Surgical Unit

JOHN SHENNAN

Wallasey, Cheshire

${ }_{*}^{*}$ The Secretary writes: "Without commenting upon the many anomalies which inevitably arise as a result of the operation of an arbitrary ceiling of $£ 8500$ per annum on incomes, it has to be reported that while the anti-inflation policy is said to be 'voluntary,' section 1(1) of the Remuneration, Charges and Grants Act, 1975, does, in fact, protect NHS employing authorities who in this way 'meddle with or alter' previously agreed salary scales for consultants embodied in their terms and conditions of service."-ED, $B M F$. 